\title{
Medidas especiales en tiempos de Covid-19: \\ la situación laboral de los empleados de hogar
}

\author{
Special measures Covid-19: \\ the employment situation of domestic workers
}

\author{
María Germana Aparicio Ruiz* \\ Doctora en Derecho Laboral \\ Universidad de Zaragoza \\ Asesora laboral
}

Recibido: 02/02/2020

Aceptado: 07/06/2020

doi: https://doi.org/10.20318/labos.2020.5774

Resumen: La reciente pandemia COVID19 ha tenido unas consecuencias a nivel sanitario, pero también económico y laboral. En este estudio, queremos destacar las consecuencias producidas en los empleados del hogar. Un sector laboral especialmente vulnerable en España, y de gran demanda para atender a familias en su conciliación familiar-laboral, y a personas mayores, afectadas en particular en esta situación de emergencia.

La especialidad del contrato de empleo doméstico en España, la facultad de desistimiento, la falta de subsidio de desempleo ha promovido una especial atención en este periodo, con el recurso a medidas económicas extraordinarias, que pueden ser punto de inflexión para revisar las carencias del contrato, así como el cuestionamiento de la ratificación del Convenio núm. 189 de la OIT.

Palabras clave: Covid-19, empleada hogar, medidas de protección laboral, OIT.

Abstract: The recent COVID19 pandemic has had consequences at the health level, but also at the economic and employment level. In this study, we would like to highlight the consequences produced on household employees. This is an especially vulnerable sector in Spain, and there is a great demand to attend to families in their work-family reconciliation, and to elderly people, who are particularly affected in this emergency situation.

The speciality of the domestic employment contract in Spain has promoted special attention in this period, with the use of extraordinary economic measures, which can be a turning point in reviewing the shortcomings of the contract, as well as questioning the ratification of ILO Convention No. 189.

Keywords: $\quad$ Covid-19, domestic worker, labour protection measures, ILO. 


\section{Peculiaridades del contrato de empleados del hogar familiar, como causa de protección en momentos de excepción}

Los acontecimientos acaecidos como consecuencia del COVID-19, han tenido repercusiones a nivel social -con la pérdida de tantas personas-, a nivel económico y laboral, con el parón forzoso o limitado para evitar mayores contagios, etc.

Indudablemente esta situación ha tenido efectos negativos y devastadores, pero también algunas consecuencias y reflexiones que considero favorables: la solidaridad de tantas personas y la actitud de servicio de tantos profesionales, la conciencia de dependencia de unas personas y profesiones con otras, etc. También desde el punto de vista laboral, ha supuesto un avance positivo para un sector profesional cada vez más necesario: los empleados de hogar. Y a la vez, se ha evidenciado además, la necesidad de avanzar en una mejora normativa en esta profesión.

\section{I.1. Un contrato especial: los empleados y empleadas del hogar.}

Bajo la protección del Real Decreto 1620/2011 se regula el Régimen Especial de empleados de hogar que supuso un gran avance respecto a la normativa anterior de 1985, si bien, hay que seguir teniendo presente su especialidad, por el tipo de relación entre empleado y empleador.

Precisamente en el caso del servicio del hogar familiar, si partimos de las notas jurídicas reguladas en el supuesto de hecho del RD 1620/2011 nos encontramos rasgos comunes al tipo general del contrato -ajenidad, dependencia, remuneración- y otros específicos que determinan la singularidad del mismo. Se pueden destacar principalmente tres, como son el lugar de prestación de los servicios, el hogar familiar; el empleador doméstico o titular del hogar familiar y el objeto del contrato, los servicios domésticos.

Tomando como base la propia Exposición de motivos del RD 1620/2011, una de las condiciones particulares de las personas que trabajan en el servicio doméstico es "el ámbito donde se presta la actividad, el hogar familiar, tan vinculado a la intimidad personal y familiar y por completo ajeno y extraño al común denominador de las relaciones laborales". Por tanto, una de las especialidades de la relación se basa precisamente en el lugar donde se desarrolla el trabajo, el hogar familiar.

En este sentido, puede detectarse que la regulación del RD 1620/2011 tiene presente como una de las especialidades de la relación, el vínculo personal basado en una especial relación de confianza. Al tiempo que resalta como novedad, en el ingreso al trabajo, la garantía y ausencia de discriminación en el acceso al empleo, conforme ya señala el Real Decreto Legislativo 3/2015, de 23 de octubre, por el que se aprueba el texto refundido de la Ley de Empleo y la Ley Orgánica 3/2007, de 22 de marzo, para la igualdad efectiva de mujeres y hombres.

En segundo lugar, la figura del contratante constituye uno de los rasgos específicos del tipo especial del servicio del hogar familiar. Esta nota característica se encuentra recogida en el art. 1.2 y 1.3 RD 1620/2011, y de modo negativo en el art. 2.1, a) excluyendo a las personas jurídicas como titulares del hogar familiar.

Resáltese que una de las especialidades estructurales de la relación laboral del servicio del hogar familiar consiste precisamente en la condición y finalidad del empleador doméstico. Quien contrata lo hace con el objetivo de cubrir una serie de necesidades básicas y vitales, como es el cuidado del hogar, de la propia persona o de la familia, hasta el punto de que esta condición es la que

\footnotetext{
${ }^{1}$ Exposición de motivos del RD 1620/11, de 14 de noviembre, por el que se regula la relación laboral de carácter especial del servicio del hogar familiar (BOE núm. 277 de 17-11-2011).
} 
ha justificado también una regulación jurídica de especial protección a un empleador que no es empresario, siempre que no vaya en detrimento del amparo del trabajador. Esta protección específica se puede garantizar no tanto dejándola a la libre autonomía de las voluntades ${ }^{2}$, sino estableciendo unas condiciones claras de contratación.

Teniendo presente la evolución de la sociedad, cada vez más se recurre a medidas jurídicas, económicas y fiscales que apoyen a la familia, como titular de contratación de estos servicios, al tiempo que se garantizan las condiciones de contratación del empleado. Y es precisamente en este ámbito donde se ha visto afectado el trabajo de los empleados domésticos, al producirse por la pandemia del COVID-19, procesos de confinamiento y aislamiento que han dificultado la continuidad en el trabajo de estos trabajadores.

En tercer y último lugar, el objeto, como sucede en el tipo común del contrato de trabajo, constituye uno de los elementos configuradores del contrato y se basa en el intercambio de servicios y el precio. Así, la expresión que utiliza el art. 1.1 ET y art. 1.2 RD 1620/2011 es la misma: "servicios retribuidos". Los servicios domésticos, en la regulación positiva, se prestan en un marco bastante amplio de "actividades". Por cuanto la domesticidad aparece ligada a la circunstancia de que los servicios sean prestados "para el hogar familiar, pudiendo revestir cualquiera de las modalidades de las tareas domésticas". Es decir, que se trata de un marco muy amplio de actividades referentes al cuidado del hogar familiar, y de las personas que en ella habitan, y por tanto de una importancia relevante, para el desarrollo de las personas.

Una vez situado el contexto de la especialidad de la relación laboral, a la que se acogen un elevado porcentaje de la sociedad, y de la que se benefician un importante número de personas y familias, con repercusión en la economía del país. Nos adentraremos en la especialidad del fin de contrato, como una de las causas de su protección particular en estos meses de pandemia.

\section{I.2. Las causas de extinción del contrato.}

En el marco de la especialidad, nos encontramos también las causas de extinción del contrato, en la que se excluyen algunas generales, y se incluye una tan específica como el desistimiento que permite la extinción en cualquier momento.

Como es bien sabido, desde el punto de vista laboral, el art. 11 RD 1620/2011 regula la extinción del contrato de trabajo del empleado doméstico, que introdujo modificaciones considerables respecto a la normativa anterior, tendentes a reforzar los derechos del trabajador.

Entre las causas de extinción del contrato laboral de los empleados del hogar, se sigue, a grandes rasgos, la normativa general. De hecho, el art. $11.1 \mathrm{RD}$ 1620/2011 remite a lo previsto en el art. $49 \mathrm{ET}^{3}$, con excepción de las causas señaladas en las letras h), i) y l) del apartado 1, que no resultan compatibles -según el legislador-con la naturaleza de la relación ${ }^{4}$.

Debido al frecuente recurso a la contratación del empleado doméstico para el cuidado de personas mayores, dentro de dichos supuestos, requiere mención especial la muerte del empleador, dado que provoca automáticamente la extinción de la relación laboral doméstica, como así se sigue

\footnotetext{
${ }^{2}$ LÓPEZ GANDÍA, J. Las relaciones especiales. Albacete: Bomarzo, 2008. p. 96.

${ }^{3}$ La extinción del contrato se regula en el capítulo III, sección 4a del ET, en los art. 49 a 57.

${ }^{4}$ Respecto a la exclusión que hace la norma, se ha planteado su cuestionabilidad al tratarse de causas compatibles con esta relación especial, dado que las circunstancias habilitantes de todas ellas pueden presentarse en el contrato de los empleados de hogar. vid. RUIZ CALDERÓN, J.A. "Puntos críticos de la nueva regulación de la relación laboral especial de servicio del hogar familiar: régimen de extinción del contrato y desprotección por desempleo". AA.VV. Cuestiones laborales de actualidad. Estudios Jurídicos en homenaje al Profesor Dr. Feliciano González Pérez. Madrid: Dykinson, 2013. p. 382.
} 
en la normativa general y se ha establecido en la doctrina judicial ${ }^{5}$. Además, por aplicación del art. $49.1 \mathrm{~g})$ ET, el trabajador tendría derecho al abono de una cantidad equivalente a un mes de salario.

Esta situación se actualiza de modo particular en este periodo en el que, como consecuencia del COVID-19 han fallecido un mayor número de personas mayores, especialmente vulnerables, como muestra el siguiente estudio estadístico ${ }^{6}$ :

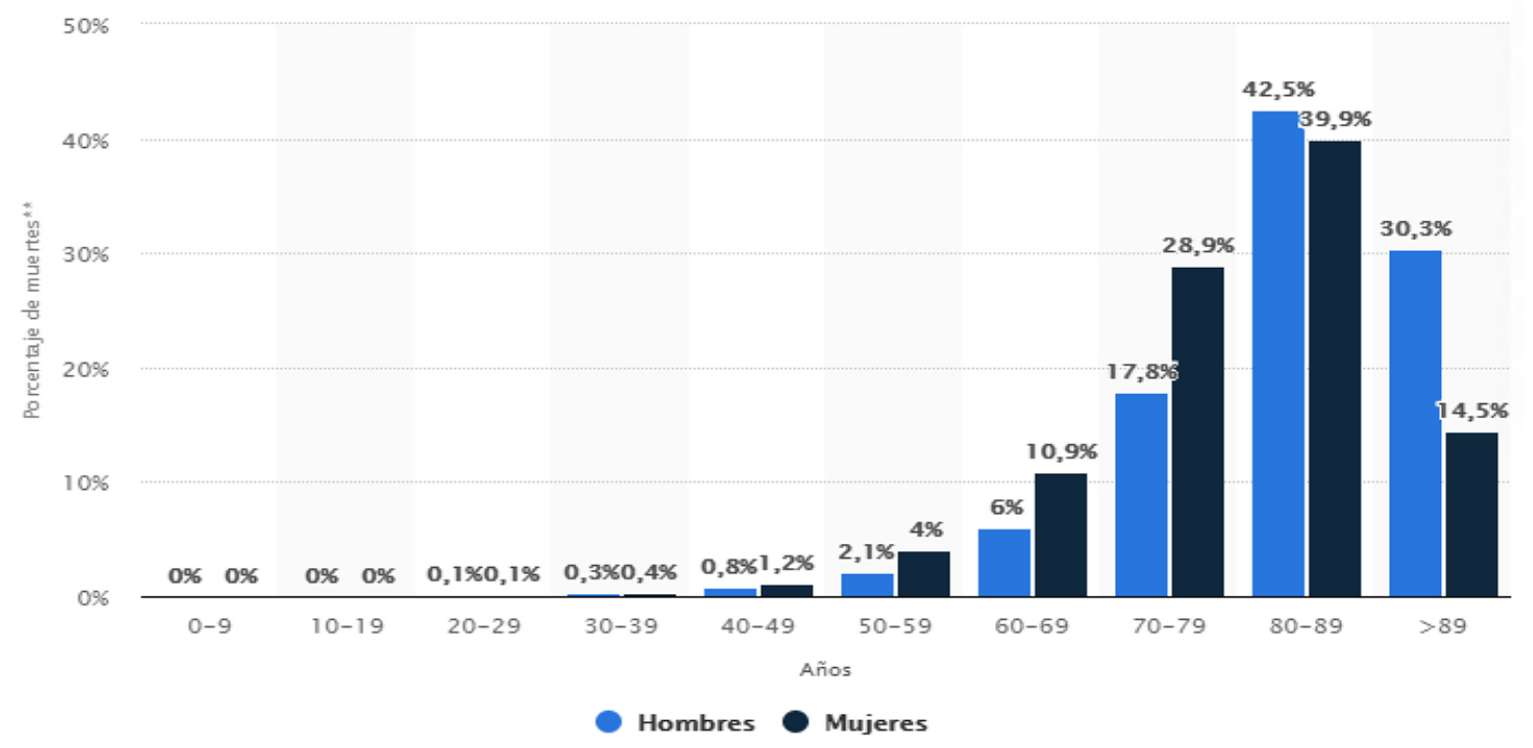

Como señala el estudio, esta estadística presenta una distribución porcentual por género y edad de las personas fallecidas por COVID-19 en Espańa a fecha de 18 de mayo de 2020. Esta enfermedad ha resultado en mayor medida letal entre la población de edades avanzadas. No por menos, más de un $80 \%$ de las muertes por COVID-19 registradas en el país hasta ese momento, correspondían a personas mayores de 70 años, tanto en el caso de los hombres como de las mujeres.

Si a esta realidad ańadimos que la contratación de empleados del hogar suele ir ligada en buena parte a personas mayores, nos encontramos con un escenario en que se han incremento el número de extinciones de este tipo de contrato, por muerte del empleador debido al coronavirus, y que se encuentran en una situación no cubierta por el subsidio extraordinario para empleadas del hogar (art. 30 RDL 11/20).

La pérdida de empleo por fallecimiento ha afectado a trabajadoras internas y también a externas que cuidan por horas y, aunque el subsidio extraordinario ha pretendido "cuidar a las que cuidan", se deja sin empleo y fuera de esta cobertura a un número amplio de personas vulnerables.

\section{I.3. La facultad de desistimiento del empleador ¿̨necesaria?}

Además de los supuestos previamente seńalados, la facultad de libre desistimiento del empleador constituye quizá la peculiaridad más destacable del régimen jurídico de extinción del contrato regulada en el art. 11.3 RD 1620/2011, que introduce dos grandes modificaciones respecto a la norma-

\footnotetext{
${ }^{5}$ STCT de 8 de octubre de 1986 (AS 9133).

https://es.statista.com/estadisticas/1125974/covid-19-porcentaje-de-fallecimientos-por-edad-y-genero-en-espana/

$\mathrm{CO}-$ VID-19: porcentaje de fallecimientos por edad y género en España en mayo de 2020.
} 
tiva de 1985. Por un lado, la exigencia de comunicación por escrito de la decisión del empleador de desistir de la relación laboral ${ }^{7}$, con manifestación clara e inequívoca de que la causa de extinción del contrato es el desistimiento y no otra. Por otro lado, se aumenta la indemnización de este supuesto, pasando de siete a doce días por ańo de servicio, con el límite de seis mensualidades.

Sigue llamando la atención la pervivencia del desistimiento cuando ha dejado de existir hace tiempo en la relación laboral ordinaria regulada en art. 49 ET, mientras que solo se encuentra presente en la relación laboral de carácter especial de alta dirección y en el servicio del hogar familiar.

En la mayoría de los estudios, se busca cuál es la raíz de esta facultad ${ }^{8} y$, en gran parte, se ha encontrado en la especialidad de la relación y en la necesidad de la mutua confianza para mantener dicha relación?.

De todos modos, al tratar de que estos motivos son los que realmente afectan a la relación y que permanecen unidos a la especialidad de la misma, habrá que precisar y tasar cuándo se alteran estas circunstancias para evitar que haya arbitrariedad por parte del empleador y que efectivamente exista una causa que motive el despido, para no dejar en una situación de indefensión al trabajador, y para crear una barrera protectora del trabajador individual frente a conductas que pueden ser fácilmente abusivas. Por tanto, interesa revisar la figura del desistimiento para que todo despido sea causal aunque la causa, por la especialidad de la materia, radique en razones como el desamparo del derecho a la intimidad, la pérdida de confianza mutua, etc.

Adviértase por tanto, que la comunicación escrita del desistimiento del empleador (art. 9.3 RD 1620/2011) es un paso adelante en garantía jurídica, sin embargo, la indeterminación de la causa que lo motiva mantiene en inseguridad al empleador.

En este sentido, la reciente STS $591 / 2020^{10}$ referida al desistimiento del empleador según el art. 11.3 RD 1620/11, y conectado con la noticia del embarazo de la empleada doméstica, declara que se trata de un despido nulo, basado en el embarazo de la empleada del hogar, y por tanto no procede el desistimiento por causa de desconfianza.

Es relevante que se determina el pago de la indemnización como despido improcedente de una relación laboral común (33 días de salario por ańos de servicio), en lugar de aplicar el previsto en art. 11.2 RD 1620/11 de la relación laboral especial del servicio del hogar (20 días de salario por año de servicio), así como el abono de los salarios de tramitación desde la fecha del desistimiento empresarial hasta la de la notificación de la sentencia de suplicación. Este recurso de casación para la unificación de doctrina ${ }^{11}$, sienta las bases de un posible cambio normativo respecto a que cualquier

\footnotetext{
${ }^{7}$ En este sentido, también resulta novedosa la remisión a la facultad de desistimiento regulada en el art. 11.3 RD 1620/2011, cuando se modifiquen determinados elementos del contrato por cambio de empleador o por traslado del hogar familiar (art. 10 RD).

${ }^{8}$ CUEVA PUENTE, C. La relación laboral especial de los empleados de hogar. Valladolid: Lex Nova, 2005. pp. 404 y ss. Hace un buen estudio doctrinal del posible fundamento del desistimiento del empleador.

9 SALA FRANCO, T. "La relación laboral especial del Servicio del Hogar Familiar y el contrato de trabajo doméstico". Relaciones Laborales, núm. 4, 1986 pp. 35-36; QUESADA SEGURA, R. El contrato de servicio doméstico. cit. pp. 76-80; CARDENAL CARRO, M. "A los 15 ańos de existencia de las relaciones laborales especiales. Un balance y una propuesta.". Aranzadi Social,. 2000, V, p. 177.

${ }^{10}$ STS 591/2020, Sala de lo Social, del 29/01/2020. No de Recurso: 2401/2017.

${ }^{11}$ Ya con la entrada en vigor de la Ley Orgánica 3/2007, de 22 de marzo, de igualdad efectiva de hombres y mujeres (LOI), la situación cambia en determinados supuestos, como es la cuestión relativa al despido de una empleada doméstica por razón de embarazo o maternidad. Puesto que, si se realiza, el art. 8 LOI seńala que constituye una discriminación directa por razón de sexo, todo trato desfavorable a las mujeres relacionadas con el embarazo o la maternidad. En cuanto al efecto, según el art. 10 LOI determina claramente que los actos que constituyan o causen discriminación por razón de sexo se considerarán nulos y sin efecto, y darán lugar a responsabilidad a través de un sistema de reparaciones o indemnizaciones que sean reales, efectivas y proporcionadas al perjuicio sufrido. Por tanto, en aplicación de esta norma, puede haber tribunales que consideren el despido como nulo y dejen sin efecto la decisión empresarial, condenando al pago de unas determinadas indemnizaciones.

${ }^{11}$ Este es el caso de la Sentencia del Juzgado de lo Social no 31 de Madrid, de 16 de abril de 2008 (AS 664), que ya supuso un cambio de especial trascendencia al aplicar el mecanismo protector que instituye la Ley de igualdad a una relación como es la de empleados de hogar, cuya regulación específica es escasamente protectora.
} 
despido sea causal, y en el caso de los empleados del hogar sea también justificado el desistimiento del empleador, provocando si no un despido improcedente o nulo.

La facultad de desistimiento en el periodo de confinamiento y de COVID-19 ha podido ser una fuente de reducción de empleos ya que, por la convivencia más estrecha en el hogar familiar propia de esta profesión, y la necesaria protección personal y familiar en periodo COVID, se ha generado la disyuntiva de prescindir de este empleo o bien, proceder al régimen de empleado interno, que en muchos caso no es posible.

\section{El Sistema Especial de los empleados del hogar en materia de Seguridad Social}

El R.D. Legislativo 8/2015, de 30 de octubre, por el que se aprobó el texto refundido de la Ley General de la Seguridad Social, incluye en el art. 250 y 251 el Sistema especial para empleados de hogar.

Como es lógico, la equiparación de derechos tiene como contrapartida el aumento progresivo de las cotizaciones ${ }^{12}$, de manera que se permita cubrir la protección de los empleados del hogar.

En este sentido, se siguen planteando dudas de si se trata de una auténtica integración o más bien es una ambigüedad, por las excepciones y peculiaridades que seguirán existiendo debidas a la especialidad de la relación laboral ${ }^{13}$.

En primer término, el art. 251 TRSS recoge la acción protectora de los empleados del hogar, que tendrán derecho a las mismas prestaciones del Régimen General de la Seguridad Social con algunas peculiaridades.

Hay que tener en cuenta que, en relación a las prestaciones ${ }^{14}$ en la normativa anterior a la Ley 27/2011, se ha conseguido, salvo las peculiaridades expresamente recogidas, la equiparación de derechos y obligaciones en materia de cobertura social de los empleados de hogar como cualquier otro trabajador por cuenta ajena:

- Como se recoge en el art. 251, a) TRSS la percepción de subsidio por incapacidad temporal, en supuestos de enfermedad común o accidente no laboral, se abonará a partir del noveno día de la baja en el trabajo, disponiendo la reforma además que este abono estará a cargo del empleador "desde los días cuarto al octavo ambos inclusive". Esto supone un gran avance respecto a la normativa anterior ${ }^{15}$ ya que el subsidio por incapacidad temporal no se percibía hasta el vigésimo noveno día.

Este subsidio, como expresaremos posteriormente, es incompatible con el subsidio extraordinario concedido con motivo del COVID-19, según se recoge en el art. 32 del RDL 11/20 de 31 de marzo, por el que se adoptan medidas urgentes complementarias en el ámbito social y económico para hacer frente a esta pandemia.

Sin embargo, hay que replantearse que esta enfermedad "poco común" ha llegado a extenderse con una facilidad y unos efectos que han provocado bajas por enfermedad en muchas profesiones.

\footnotetext{
${ }^{12}$ En el caso de los empleados del hogar, nos encontramos con unas reglas de cotización, con 10 tramos según el número de horas trabajadas y el salario euros/mes. También tiene como particularidad la posibilidad de que el empleado asuma esta obligación en caso de prestar servicios para varios empleadores, menos de $60 \mathrm{~h}$ al mes para cada uno de ellos. Interesa resaltarlo en estos momentos porque si la empleada no cumple con el alta y cotización, las medidas específicas de protección en la crisis sanitaria no le alcanzarán.

${ }^{13}$ SELMA PENALVA, A., "Novedades en el Régimen de Seguridad Social de los Empleados del Hogar y su comparación con las propuestas de reforma anteriormente anunciadas". Actualidad Laboral, núm. 2, I-2012. pp. 145-148.

${ }^{14}$ LÓPEZ GANDÍA, J. - TOSCANI JIMÉNEZ, D. El nuevo régimen laboral y de Seguridad Social de los trabajadores al servicio del hogar familiar. Madrid: Bomarzo, 2012. pp. 89-94.

${ }^{15}$ MINARRO YANINI, M. "La nueva regulación de la relación laboral de carácter especial del servicio del hogar familiar: una mejora mejorable (II)”. Relaciones Laborales, núm. 5, Sección Legislación, Año 28, tomo 1, Editorial La Ley, III-2012. pp. 81-82.
} 
Sería lógico, que no fuera incompatible con el subsidio extraordinario por COVID-19, en un sector tan vulnerable y castigado profesionalmente.

- Por otro lado, el art. 251, d) TRSS señala que la acción protectora del sistema especial de empleadas de hogar no comprende la prestación por desempleo. En el caso de que se contrate una empleada de hogar a través de una empresa dedicada a esta actividad, será la empresa quien se encargue de la cotización. En esta línea, es uno de los deberes que el RD 1620/2011 atribuye a un grupo de expertos: la viabilidad de establecer un sistema de protección por desempleo para el colectivo de personas afectadas por la norma, que se adapte a "las peculiaridades de la actividad del servicio del hogar familiar". La preocupación por el coste que la medida puede tener, ya se constató también en las propuestas de reforma del Pacto de Toledo y así se planteó en la reforma de la Ley 27/2011, que lleva a la norma a efectuar una manifestación expresa de que dicha medida debía garantizar "los principios de contributividad, solidaridad y sostenibilidad financiera".

\subsection{Ausencia de prestación por desempleo}

Los empleados del hogar están excluidos de la prestación por desempleo (art. 251, d) TRSS), con el alto riesgo que tienen del mismo, a través de la facultad de desistimiento del empleador. Esta exclusión pudo tener cierta justificación en 1969 cuando se reguló el REEH porque no eran sujetos de una relación laboral ${ }^{16}$, sin embargo, actualmente carece de toda justificación ${ }^{17}$ ya que se trata de una relación laboral que debería acogerse a lo establecido para los demás trabajadores. Si bien es cierto que puede generar situaciones especialmente propicias al fraude, por la dificultad de someter la relación a mecanismos de control ${ }^{18}$. Aun así, el empleado doméstico debe inscribirse en el SEPE, no solo para recibir oferta de empleo sino también para participar en cursos de formación.

Lo cierto es que el trabajo en el hogar familiar representa la actividad que ocupa a un mayor contingente de personas y lleva inherente ciertos riesgos profesionales particulares. Por tanto, las acciones de protección deberían revestir unas formas y contenidos específicos donde se concilie el domicilio privado con una serie de medidas de seguridad e higiene que garanticen el trabajo del empleado del hogar ${ }^{19}$, sin que lo conviertan en un centro donde la Inspección de trabajo pueda entrar en cualquier momento.

La ausencia de la protección por desempleo -ya contenida en el Régimen Especial de Empleados de Hogar (REEH), antes de ser integrado en el RGSS- choca ahora, sin embargo, con la progresiva extensión de la protección por desempleo a colectivos de trabajadores por cuenta ajena que han estado o están aún hoy insertos en regímenes especiales y que antes carecían de esta previsión ${ }^{20}$. Esta falta de cobertura implica un grave perjuicio para las empleadas de hogar que, por el momento, permanece tal cual sin que parezca próxima su inclusión.

\footnotetext{
${ }^{16}$ ESPUNY TOMÁS, M.J. "El servicio doméstico: la historia de una exclusión jurídica continuada”. Relaciones laborales y empleados de hogar. Reflexiones jurídicas. Dikynson, 2014. pp. 27-60.

${ }^{17}$ LUJÁN ALCARAZ, J. "El Régimen Especial de la Seguridad Social de los Empleados de Hogar.". Aranzadi Social. p. 88.

${ }^{18}$ SELMA PENALVA, A., Novedades en el Régimen de Seguridad Social de los Empleados del Hogar y su comparación con las propuestas de reforma anteriormente anunciadas. Actualidad Laboral, núm. 2, Sección Estudios, T. 1, La Ley, I-2012. p. 160.

${ }^{19}$ SEMPERE NAVARRO, A.V; GARCÍA BLASCO, J.; GONZALEZ LABRADA, M.; CARDENAL CARRO, M. Derecho de la Seguridad y Salud en el trabajo. Madrid: Civitas, 2001. pp. 71-72.

${ }^{20}$ SANZ SAEZ, C.: La protección social de las empleadas de hogar. La desaparición del Régimen Especial de la seguridad Social y su integración en el Régimen General como Sistema Espacial: análisis actual y de futuro. Albacete. Bomarzo, 2017.
} 
La falta de protección por desempleo representa una merma de considerable repercusión en el marco protector del trabajo doméstico y se encuentran en el epicentro de todos los problemas de ratificación del Convenio de la OIT. Y ello pese a que, no podemos dejar de señalar, en este sentido, que hasta la Unión Europea ha instado a los Estados miembros de la Unión a que procedan a su ratificación ${ }^{21}$.

\section{Medidas en favor de los empleados y empleadas de hogar, en momentos de excepcionalidad}

La importancia de esta profesión para las personas, familias y la sociedad, su creciente protección jurídica, todavía llena de excepcionalidades, provoca que en situaciones de emergencia como la actual se quiera proteger a un sector vulnerable también desde el punto de vista laboral.

La crisis sanitaria que estamos padeciendo como consecuencia del COVID-19 está teniendo un impacto directo en la economía y en la sociedad, y en el día a día de los ciudadanos. Aunque las medidas tienen un denominador común de protección del empleo, la ayuda a los más vulnerables y el mantenimiento del tejido productivo, se amplían y complementan con las contenidas en el Real Decreto-Ley 11/2020, de 31 de marzo ${ }^{22}$ por el que se adoptan medidas urgentes complementarias en el ámbito social y económico para hacer frente al COVID-19, con el objetivo de implementar medidas de carácter social dirigidas al apoyo de trabajadores, consumidores, familias y colectivos vulnerables.

Será el art. 30, 31 y 32, así como la DT $3^{\text {a }}$ del RDL 11/20 quien regule estas medidas específicas en el sector en estudio de los empleados de hogar. En primer lugar, resaltaremos su contenido, para posteriormente analizar sus carencias.

En el art. 30 se recogen los beneficiarios del subsidio extraordinario por falta de actividad para las personas integradas en el Sistema Especial de Empleado de Hogar del Régimen General de la SS. Como bien puede apreciarse se trata de un subsidio extraordinario y se aplica "por falta de actividad".

Los requisitos exigen una regularidad previa del contrato, como es lógico: estar dados de alta en la Seguridad Social ${ }^{23}$, y que se den alguna de las siguientes causas:

a) Dejar de prestar servicios total o parcialmente: hecho que en parte es cierto por tratarse de un empleo altamente parcial y por horas, que en circunstancias de emergencia se ha visto conveniente prescindir de él en muchos hogares para evitar contagios mayores, si bien, también ha provocado en muchos empleados de una atención continuada en régimen de internado.

La manera de acreditar este hecho causante es a través de una declaración responsable, firmada por la persona empleadora o personas empleadoras, respecto de las cuales se haya producido la disminución total o parcial de servicios (art. 30.2).

b) O bien, que se produzca una extinción del contrato por despido del trabajador (art. 49, 1 k TRSS) o por facultad de desistimiento (art. 11.3 RD 1620/11).

\footnotetext{
${ }^{21}$ GRAU PINEDA, C. "De sirvientas a trabajadoras: la necesaria ratificación del Convenio 189 OIT sobre trabajo decente para las trabajadoras y los trabajadores domésticos" Lex Social, 2019. Vol. 9, núm 2/19.

${ }^{22}$ BOE de 1 de abril y corrección de errores BOE de 9 de abril de 2020. Bien es cierto que para el resto de trabajadores se fueron aprobando medidas desde el 17 de marzo de 2020, pero el colectivo de trabajadoras domésticas hubo de esperar hasta el 1 de abril de 2020, día en el que por primera vez una norma se refiere a la necesidad de protección frente a la inactividad, y hasta el 30 de abril (BOE 2 de mayo) para que se aprobara el procedimiento para la tramitación de esta protección vinculada al COVID-19. GARCÍA TESTAL, E. “Trabajo doméstico y COVID-19”. Actualidad jurídica iberoamericana. núm.12 bis, mayo 2020. pp. 712-723.

${ }^{23}$ GARCÍA TESTAL, E. “Trabajo doméstico y COVID-19”. Op. Cit. Como se señala en este artículo, las medidas del RD, dejan sin protección a más de un tercio de personas que trabajan en este sector en una situación de informalidad.
} 
Estos supuestos podrán acreditarse por medio de carta de despido, comunicación del desistimiento de la empleadora o empleador, o documentación acreditativa de la baja en el Sistema Especial de Empleados del Hogar del Régimen General de la Seguridad Social (art. 30. 2 in fine).

Nuevamente, por la peculiaridad del contrato, y la confianza exigida en este ámbito, se reafirma el recurso a la facultad de desistimiento como una causa habitual de finalizar un contrato.

En el art. 31 se especifica la cuantía del subsidio. Si bien, el cálculo lo realizará la Seguridad Social. En todo caso, la norma parte de que las empleadas domésticas (puesto que la inmensa mayoría son mujeres) pueden estar trabajando en una o varias casas, distinguiendo entre uno y otro supuesto. También diferencia según que haya cesado totalmente la actividad o que se mantenga aunque de forma reducida. En los dos casos se cobra la ayuda.

Como señala el RDL 11/20, los supuestos para percibir el subsidio serán:

a) La pérdida total de un único trabajo. La base reguladora diaria de la prestación estará constituida por la base de cotización del empleado de hogar correspondiente al mes anterior del día en que se ha suspendido o cesado en la prestación de servicios domésticos dividida entre 30, que es el número medio de días del mes.

La cuantía obtenida está limitada, no pudiendo ser superior al salario mínimo interprofesional, excluida la parte proporcional de las pagas extraordinarias.

b) La pérdida parcial de un único trabajo: la cuantía del subsidio indicada se percibirá en proporción directa al porcentaje de reducción de jornada que haya experimentado la persona trabajadora.

c) La pérdida total de varios trabajos: se calculará la base reguladora correspondiente a cada uno de los distintos trabajos y se aplicará a cada una de las distintas bases el porcentaje del $70 \%$. La cuantía total que resulte tendrá el límite señalado.

d) La pérdida parcial en todos o alguno de los trabajos: se aplicará a cada una de las cantidades obtenidas el porcentaje de reducción de jornada que haya experimentado la persona trabajadora en la actividad correspondiente; si la cuantía total del subsidio, previamente a la aplicación de dichos porcentajes, alcanzara el importe del SMI, excluida la parte proporcional de las pagas extraordinarias, se prorrateará dicho importe entre todos los trabajos desempeñados atendiendo a la cuantía de las bases de cotización durante el mes anterior al hecho causante de cada uno de ellos, aplicándose a las cantidades así obtenidas el porcentaje de reducción de jornada que haya experimentado la persona trabajadora en la actividad correspondiente.

El pago de dicho subsidio se hará por periodos mensuales, desde la fecha del nacimiento del derecho.

Por otro lado, el art. 32 señala las compatibilidades e incompatibilidades de este subsidio. Es compatible con las retribuciones que se sigan percibiendo ya sea cuando se trabaja por cuenta ajena (para un solo empleador normalmente) o por cuenta propia (para varias empleadoras). El único requisito es que la suma total de ingresos, los de la ayuda y el sueldo o las horas que se pagan no sea superior al Salario Mínimo Interprofesional, es decir, a 950 euros.

La incompatibilidad se da con el subsidio por incapacidad temporal (es decir, con una baja) y con el permiso retribuido recuperable que también está previsto para estas situaciones regulado en el Real Decreto-Ley 10/2020 (en adelante, RDL 10/2020) ${ }^{24}$.

${ }^{24}$ CEF LABORAL SOCIAL. "Publicadas y en vigor nuevas medidas complementarias en el ámbito sociolaboral para paliar 
La D Transitoria $3^{\text {a }}$ señala que dicho subsidio excepcional tendrá aplicación con carácter retroactivo, a los hechos causantes definidos aun cuando se hayan producido con anterioridad a su entrada en vigor. Corresponde al Servicio Público de empleo estatal habilitar los procedimientos y mecanismos adecuados para hacerlo para lo que dispone de un mes desde el 1 de abril.

La Resolución de 30 de abril de 2020, del Servicio Público de Empleo Estatal desarrolla el procedimiento para la tramitación de solicitudes del subsidio extraordinario por falta de actividad para las personas integradas en el Sistema Especial para Empleados de Hogar del Régimen General de la Seguridad Social regulado en el Real Decreto-ley 11/2020, de 31 de marzo, por el que se adoptan medidas urgentes complementarias en el ámbito social y económico para hacer frente al COVID-19.

La documentación necesaria se desglosa en la web del SEPE ${ }^{25}$, con el modelo de solicitud, la declaración responsable de la persona empleadora de personas trabajadoras del Sistema Especial para Empleados de Hogar, así como las instrucciones y documentación para cumplimentarlo adecuadamente.

Estas medidas extienden su vigencia desde el 2 de abril hasta un mes después del fin del estado de alarma, sin perjuicio de que pueda acordarse su prórroga y de que se hayan de respetar los plazos determinados que en su caso se establezcan para medidas concretas.

\subsection{Carencias de las medidas en favor de los empleados y empleadas del hogar}

Junto con el subsidio extraordinario a los empleados del hogar, afectados por el COVID19, cabe reflexionar sobre las carencias que estas medidas provocan en este sector, respecto al resto de profesiones.

1. En cuanto a las características de esta protección, lo primero que hay que resaltar es que no se está aprobando una extensión de la protección por desempleo vigente para el resto de trabajadores, con el mismo contenido, requisitos y formalidades. No puede afirmarse que se haya introducido la protección por desempleo en el trabajo doméstico, sino exclusivamente que se ha aprobado una medida extraordinaria de atención a los períodos de inactividad, puntual y vinculada a la actual crisis sanitaria ${ }^{26}$.

El acceso al subsidio extraordinario en caso de extinción o por facultad de desistimiento no se trata de una suspensión o cese temporal, sino que el empleador le ha despedido por cualquier causa (por ejemplo, no necesitar ya sus servicios a consecuencia de la crisis sanitaria, o por cuidar de personas mayores que hayan fallecido) o el empleado de hogar se ha despedido (ha desistido del contrato) para evitar contagios, cuidar de su familia o cualquier otra causa.

Esta medida choca con la regulación previa del RDL 9/2020, de 27 de marzo, en el que en sus artículos $2^{\circ}$ y $5^{\circ}$ se prohíben los despidos durante el estado de alarma. El Gobierno establece que el despido alegando la crisis del COVID-19 es improcedente. Es decir, desde el 27 de marzo, automáticamente se considera "no justificada" la alegación empresarial de despido por la situación económica u organizativa por el COVID-19. La consecuencia será la condena al pago de una indemnización equivalente a 33 días de salario por año trabajado, con un máximo del sueldo de 2

los efectos derivados del COVID-19". 2 de abril de 2020. Disponible en: https://www.laboral-social.com/COVID-19-RDL11-2020-medidas-complementarias-subsidio-empleadas-hogar-desempleo-contratos-temporales-IT-confinamiento-total-cuotasautonomos-moratoria-aplazamiento.html

${ }^{25}$ Publicado en: http://www.sepe.es/HomeSepe/COVID-19/subsidio-extraordinario-personas-empleadas-hogar.html

${ }^{26}$ GARCÍA TESTAL, E. “Trabajo doméstico y COVID-19”. Op. Cit. p. 717. 
años. Esta medida no se aplica en el caso de los empleados del hogar, que podrán ser despedidos, y como tal, solicitar un subsidio extraordinario, pero al dar por válido el despido, dificulta la vuelta al empleado del hogar, en las mismas condiciones anteriores, y además sin subsidio de desempleo. Realmente nos encontramos con una mejora de su situación pero no comparable con las ventajas del resto de profesiones por cuenta ajena.

2. La forma de establecer el porcentaje en el subsidio extraordinario para empleadas del hogar es más perjudicial para este sector que para el resto de empleos. De la lectura del art $31 \mathrm{RD}$ 11/20 podemos indicar que, como la mayoría de los subsidios de la Seguridad Social, la forma de determinarlo será aplicando un porcentaje o tipo a una base reguladora. En este sentido, este "subsidio extraordinario" se despega del subsidio por desempleo ${ }^{27}$ y se asemeja más a la determinación de la prestación contributiva, porque no usa el indicador público de renta de efectos múltiples, sino una base reguladora que tiene en cuenta la cotización anterior del empleado del hogar y por tanto con perjuicio para los empleados.

3. Por otro lado, el subsidio extraordinario se considera incompatible con el de incapacidad temporal. Llama la atención que así se imponga en las circunstancias de pandemia actual. Si el empleado o empleada está enfermo por el coronavirus o se encuentra en situación de aislamiento, se puede tramitar su parte de baja médica. En este caso se pagará el $75 \%$ de la base de cotización durante toda la baja. Sin embargo no podrá percibir el subsidio extraordinario por incompatibilidad. A mi juicio, podría ser compatible en las condiciones y cuantía que se señala para el resto de retribuciones, por el carácter de enfermedad común en este periodo extraordinario de COVID-19.

A esto se suma el hecho de que el empleado de hogar no podrá ausentarse si un familiar enferma y necesita cuidados. Solo será remunerado con un máximo de dos días. Y lo que ha sido más frecuente: con el cierre de los centros educativos, si la empleada tiene hijos a cargo, en el caso de que no se logre un acuerdo con su empleador o empleadores, su ausencia no es retribuida. Resulta difícil gestionar estar realidad tan cotidiana en que se requiere una conciliación familiar y laboral también para el empleado. Por supuesto, podemos cuestionarnos sobre la aplicación a esta profesión del permiso retribuido recuperable aprobado en RDL 10/2020, pero difícilmente se puede aplicar ante la prestación de unos servicios que son necesarios de modo diario (limpieza, comida, cuidado de personas mayores, etc.), y que no se pueden posponer a tiempos mejores.

Además, la persona empleada si -por cualquier motivo- ha podido contactar con gente cercana al COVID, pero no hay garantía de contagio, tampoco podrá ponerse en cuarentena de forma voluntaria, ya que no podrán cobrar el salario de esos días, y no cobrarán tampoco ninguna prestación del sistema, ya que está únicamente prevista para los casos de aislamiento y de contagio.

Como conclusión, nos encontramos con medidas que favorecen a los empleados del hogar, pero que ponen en evidencia las carencias y falta de equiparación con otras profesiones. Y en este sentido, surge de nuevo la necesidad de solicitar una mejora normativa en el futuro, al margen de situaciones pandémicas.

${ }^{27}$ GARCÍA TESTAL, E. “Trabajo doméstico y COVID-19”. Actualidad jurídica iberoamericana. núm.12 bis, mayo 2020. pp. 712-723. Como se ha indicado, no puede afirmarse que se haya introducido la protección por desempleo en el trabajo doméstico, sino exclusivamente que se ha aprobado una medida extraordinaria de atención a los períodos de inactividad, puntual y vinculada a la actual crisis sanitaria. 


\section{Repercusiones laborales en el futuro}

En un periodo generalizado de crisis sanitaria, social y económica, se ha puesto en evidencia los sectores laborales más vulnerables, y a la vez, los más necesarios en la atención de personas.

En situaciones como la presente se ha tenido que recurrir a medidas extraordinarias como la actual para los empleados del hogar, que encuadrarían en un marco ordinario, si esta situación diera lugar al estudio de las siguientes medidas:

a) El estudio de las condiciones más objetivas para la facultad de desistimiento

b) La conveniente prestación por desempleo a los empleados del hogar.

c) La ratificación del Convenio núm 189 de la OIT, y prever como marco en el ámbito doméstico los objetivos de desarrollo sostenible ${ }^{28}$.

\subsection{Objetivación de la facultad de desistimiento.}

Respecto a la facultad de desistimiento del empleador doméstico, convendría estudiar, como se ha dicho anteriormente, precisar y tasar cuándo se alteran las circunstancias que motivan el despido para no dejar en una situación de indefensión al trabajador y para crear una barrera protectora frente a conductas que pueden ser fácilmente abusivas. Por tanto, interesa revisar la figura del desistimiento para que todo despido sea causal aunque la causa, por la especialidad de la materia, radique en razones como el desamparo del derecho a la intimidad, la pérdida de confianza mutua, o bien haya causas económicas y objetivas, organizativas o de conveniencia del empleador que requieran extinguir el contrato. Y es que, el supuesto de desistimiento por pérdida de confianza, sin justificar causa, se considera que en realidad oculta un despido ${ }^{29}$. Lo cual viene a reforzarse con lo establecido en el Convenio n. 158 de la OIT que exige alegar causa para la terminación de un contrato ${ }^{30}$.

Además, la necesidad de una causa que ampare el despido se refuerza con la existencia de unos límites al desistimiento, como la presencia de una causa lícita -no contraria a las leyes, moral u orden público-, el respeto a los derechos fundamentales (raza, sexo, religión, etc.) y las libertades públicas del trabajador (libertad sindical, ideológica, religiosa, etc.), salvo que exista una concatenación entre estos derechos y la confianza necesaria en la idoneidad del trabajador para satisfacer la finalidad que el empleador persigue al contratar. De manera que, en este ámbito juega un papel importante la Ley Orgánica 3/2007, de 22 de marzo, para la igualdad efectiva de mujeres y hombres en donde se debe conjugar la protección de la confianza necesaria en la relación con evitar cualquier discriminación del trabajador, según establece el título IV que recoge el derecho al trabajo en igualdad de oportunidades. Así lo avala la jurisprudencia reciente generando en determinadas situaciones a la nulidad del mismo despido, amparado en un desistimiento (STS 591/2020) ${ }^{31}$.

${ }^{28}$ QUINTERO LIMA, G. "El trabajo de servicio doméstico como una realidad jurídica inevitable”. Lex Social, vol 9 , núm 2 (2019), pp. 2-6. El presente estudio introduce el volumen monográfico de artículos doctrinales dedicados al trabajo del servicio doméstico. Como introducción, da una proyección sobre lo que ha constituido un Seminario Permanente sobre Trabajo Doméstico desde 2017, con aportaciones valiosas de cara al futuro, para afrontar una "realidad inevitable" como es la importancia del cuidado en el hogar. En torno a la idea del Trabajo Decente (Objetivo de Desarrollo Sostenible (ODS en adelante) 8 de la Agenda 2030 de Naciones Unidas), el fin de la pobreza (ODS 1) y la igualdad de género (ODS 5); algo todo que se alimenta del Convenio 189 de la OIT de 2011, sobre el trabajo decente para las trabajadoras y los trabajadores domésticos.

${ }^{29}$ RUANO ALBERTOS, S. "Declaración de nulidad del despido de una empleada de hogar (Comentario de la Sentencia del Juzgado de lo Social no 31 de Madrid, de 16 de abril de 2008)”. Aranzadi Social,. 2008, p. 45.

${ }^{30}$ Convenio no 158 de la OIT sobre la terminación de la relación de trabajo por iniciativa del Empleador (ratificación en BOE de 29 de junio de 1985).

${ }^{31}$ STS 591/2020, Sala de lo Social, del 29/01/2020. No de Recurso: 2401/2017. 
A su vez, como señala un estudio reciente, hay que hacer hincapié en que nuestro Estado de bienestar está construido sobre cuatro pilares clásicos: la educación, la sanidad, la protección por desempleo y las pensiones públicas, a los que hace unos años se añadió el de las llamadas "políticas de dependencia" ${ }^{32}$. Es cierto que se han tomado medidas que faciliten la conciliación de la vida familiar y laboral, pero en este contexto queda un largo recorrido para proteger la contratación o conservación del empleo de trabajadores con responsabilidades familiares.

\subsection{La prestación por desempleo}

Con motivo del RDL 11/20 se ha intentado proteger a este sector mediante un subsidio, pero no se aprueba una protección por desempleo vigente en el resto de profesiones. Se trata más bien de una medida extraordinaria de atención a los períodos de inactividad específica unida a la actual pandemia, como ya se ha comentado.

Esta situación de especialidad choca respecto a la progresiva acogida de la prestación de desempleo para otros trabajadores por cuenta ajena que han estado o continúan en Regímenes especiales (sistema agrario, ferroviario, minería del carbón, artistas) y que antes carecían de esta previsión ${ }^{33}$.

La prestación por desempleo se encuadraría en el marco de la Seguridad Social, y concretamente del Sistema especial de empleo doméstico, cuyo estudio está abierto como ya se propuso en RD 1620/2011 para que un grupo de expertos considere la viabilidad de establecer un sistema de protección por desempleo para el colectivo de personas afectadas por la norma, que se adapte a "las peculiaridades de la actividad del servicio del hogar familiar". Sin embargo, pesan más los motivos económicos particulares que la justificación laboral y de necesidad de protección social en un Estado de Derecho social y bienestar. El apoyo a este sector vulnerable pasa por el reconocimiento de un derecho aplicable a todas las profesiones (la prestación por desempleo) y la búsqueda de mecanismos acordes para que pueda mantenerse económicamente no solo por parte del empleador particular, sino también con medidas económicas supletorias.

\subsection{Ratificación del Convenio núm. 189 OIT.}

Por otro lado, como bien es sabido, el Convenio núm. 189 de la OIT sobre el trabajo decente para las trabajadoras y los trabajadores domésticos y la Recomendación núm. $201^{34}$ de 2011, supuso un avance a nivel internacional de protección ${ }^{35}$. Así, esta normativa internacional aporta primeramente que los empleados domésticos sean reconocidos como trabajadores y obtengan el derecho a una

${ }^{32}$ RODRIGUEZ COPÉ, M.L. "Conciliación y trabajo doméstico: un reto para las políticas socio-laborales del s. XXI. El decisivo papel de los Tribunales de Justicia”. Lex Social 2019 Vol. 9 núm 2/19. pp. 212-249.

${ }^{3}$ SANZ SAEZ, C.: La protección social de las empleadas de hogar. La desaparición del Régimen Especial de la seguridad Social y su integración en el Régimen General como Sistema Espacial: análisis actual y de futuro, Bomarzo, 2017.

${ }^{34} \mathrm{El}$ Convenio define qué debe entenderse por trabajo y trabajador doméstico, tratándose en el primer caso del realizado en un hogar u hogares, o para los mismos, y referido el segundo a toda persona "de género femenino o masculino", que realiza un trabajo doméstico "en el marco de una relación de trabajo". Adviértase, por lo demás, que el Convenio recoge gran parte de los derechos establecidos en otros Convenios de la OIT y los aplica ahora a los trabajadores domésticos. http://www.ilo.org/dyn/normlex/ es/f?p=1000:12100:0::NO::P12100_ILO_CODE:C189

${ }^{35}$ Impacto del Convenio núm. 189 OIT sobre la igualdad de género, entrevista a Directora del programa sobre las condiciones de trabajo y de empleo de la OIT. http://www.ilo.org/ilc/ILCSessions/100thSession/mediacentre/articles/WCMS_158389/lang--es/ index.htm 
protección mínima, al menos desde el punto de vista legal ${ }^{36}$, pero todavía estamos a la espera de su ratificación por España.

A través de este Convenio, el trabajo decente se ha convertido en un objetivo universal y ha sido integrado en las más importantes declaraciones de derechos humanos, ampliamente reflejadas en la Agenda 2030, para la que el reconocimiento de los derechos al colectivo de empleadas de hogar es uno de los pilares del desarrollo sostenible ${ }^{37}$. En este sentido, es fundamental corregir las desigualdades existentes en el terreno del trabajo doméstico y de cuidados para lograr muchos otros objetivos. En la Agenda $2030^{38}$ se integran los objetivos de desarrollo sostenible (en adelante ODS20), que son aquellas pautas internacionales que le permiten a los Estados alinearse con el fin de que todos tengan una constante de crecimiento y desarrollo.

Pues bien, dentro del ODS núm. 5.4 se encuentra la necesidad de reconocer y valorar los cuidados y el trabajo doméstico no remunerados mediante servicios públicos, infraestructuras y políticas de protección social, y promoviendo la responsabilidad compartida en el hogar y la familia, según proceda en cada país.

La novedad radica ahora en que lo que se propone es, de un lado, poner en valor el cuidado y el trabajo doméstico no remunerado reconociéndolo y conectándolo con la reducción de la carga asociada a éste con el fin de que las mujeres aumenten su productividad y dispongan de más tiempo. Pero también asociándolo a la redistribución del trabajo entre las mujeres y los hombres en el seno de la familia, así como entre ésta y otras instituciones dedicadas a la prestación de cuidados. Una estrategia dirigida a invertir en servicios de cuidados que contribuiría a la creación de nuevos empleos en el sector asistencial y a resolver la falta de oportunidades de empleo respecto de las mujeres que caracteriza a muchos países.

Este marco mundial se presenta en un momento de crisis económica, pero no de crisis de cuidados. El esfuerzo de mejora de las condiciones de vida, puede ser palanca de crecimiento económico. Según el reciente informe de la OIT sobre tendencias del empleo femenino $2018^{39}$ las exigencias abrumadoramente desiguales que pesan sobre las mujeres respecto de las responsabilidades domésticas y de atención continúan manifestándose como desigualdades en el mercado laboral en el tipo de puestos de trabajo disponibles para las mujeres y en los que pueden gozar de empleo duradero. La ratificación del Convenio 189, además de ser una cuestión de justicia social, es importante también en términos económicos y de seguridad social.

La no ratificación del Convenio 189 está funcionando, de facto, como el elemento actual de unidad fundamental del movimiento de defensa de los derechos de las empleadas de hogar que han centrado sus reivindicaciones en la necesidad de incorporar la protección por desempleo, pero también en la necesidad de fomentar, desde las instituciones públicas, el asociacionismo y sindicación de las empleadas de hogar o de promover organizaciones de empleadores e intermediarios con los que poder negociar sus condiciones laborales ${ }^{40}$.

Por último, si una situación de emergencia económica, sanitaria y social como la que ha provocado el COVID19, ha salido al paso de un sector vulnerable como son los empleados del ho-

\footnotetext{
${ }^{36}$ Entrevista a la Directora del programa sobre las condiciones de trabajo y de empleo de la OIT. http://www.ilo.org/ilc/ILCSessions/100thSession/media-centre/articles/WCMS_158389/lang--es/index.htm

${ }^{37}$ La Meta 5.4 insta a adoptar un conjunto de políticas para reconocer y valorar el trabajo doméstico y de cuidados no remunerado.

${ }^{38}$ La Agenda para el desarrollo para después de 2015 fue aprobada por la Asamblea General de Naciones Unidas y dentro de la misma se incardinan los 17 Objetivos de Desarrollo Sostenible y las 169 metas, conexas, de carácter integrado e indivisible que pretenden hacer realidad los derechos humanos de todas las personas y alcanzar la igualdad entre los géneros y el empoderamiento de todas las mujeres y niñas. Para ello ambos conjugan las tres dimensiones del desarrollo sostenible: económica, social y ambiental.

${ }^{39}$ OIT: Perspectivas sociales y del empleo en el mundo: tendencias del empleo femenino 2018, OIT, 2018, p. 13.

${ }^{40}$ GRAU PINEDA, C. "De sirvientas a trabajadoras: la necesaria ratificación del Convenio 189 OIT sobre trabajo decente para las trabajadoras y los trabajadores domésticos”. Lex Social, vol 9, núm 2 (2019).
} 
gar, una profesión de servicio altamente necesaria, nos debe llevar a una reflexión de sobre la conveniencia de revisar las condiciones laborales, de seguridad y de ayuda económica, para impulsar este empleo que facilite la vida familiar, la conciliación familia y trabajo, y por tanto y a su vez, relanzar otras profesiones para el crecimiento económico.

\section{Bibliografía}

APARICIO RUIZ, M. La profesionalización de los empleados al servicio del hogar familiar. Desde el contraste comparado de la normativa francesa. Ed. Eolas. 2014.

CARDENAL CARRO, M. "A los 15 años de existencia de las relaciones laborales especiales. Un balance y una propuesta.". Aranzadi Social,. 2000, V.

CUEVA PUENTE, C. La relación laboral especial de los empleados de hogar. Valladolid: Lex Nova, 2005. pp. 404 y ss.

ESPUNY TOMÁS, M.J. "El servicio doméstico: la historia de una exclusión jurídica continuada”. Relaciones laborales y empleados de hogar. Reflexiones jurídicas. Dikynson, 2014. pp. 27-60.

FERNÁNDEZ DÍEZ, A. "Extinción de la relación laboral especial del servicio de hogar familiar". Lex Nova. VI-2012.

GARCÍA TESTAL, E. “Trabajo doméstico y COVID-19”. Actualidad jurídica iberoamericana. Núm. 12 bis, mayo 2020. pp. 712-723.

GRAU PINEDA, C. "De sirvientas a trabajadoras: la necesaria ratificación del Convenio 189 OIT sobre trabajo decente para las trabajadoras y los trabajadores domésticos” Lex Social, 2019. Vol. 9, núm 2/19.

MINARRO YANINI, M. "La nueva regulación de la relación laboral de carácter especial del servicio del hogar familiar: una mejora mejorable (II)". Relaciones Laborales, núm. 5, Sección Legislación, Año 28, tomo 1, Editorial La Ley, III-2012.

LÓPEZ GANDÍA, J. Las relaciones especiales. Albacete: Bomarzo, 2008.

LÓPEZ GANDÍA, J. - TOSCANI JIMÉNEZ, D. El nuevo régimen laboral y de Seguridad Social de los trabajadores al servicio del hogar familiar. Madrid: Bomarzo, 2012.

LUJÁN ALCARAZ, J. “El Régimen Especial de la Seguridad Social de los Empleados de Hogar.”. Aranzadi Social. p. 88.

MENÉNDEZ SEBASTIÁN, P. "Despido disciplinario o desistimiento empresarial en el trabajo al servicio del hogar familiar". Civitas. Revista española de derecho del trabajo. Núm. 119. 2003. pp. 691-710.

RUIZ CALDERÓN, J.A. "Puntos críticos de la nueva regulación de la relación laboral especial de servicio del hogar familiar: régimen de extinción del contrato y desprotección por desempleo". AA.VV. Cuestiones laborales de actualidad. Estudios Juridicos en homenaje al Profesor Dr. Feliciano González Pérez. Madrid: Dykinson, 2013.

QUESADA SEGURA, R. El contrato de servicio doméstico. La Ley-Actualidad 1991.

QUINTERO LIMA, G. "El trabajo de servicio doméstico como una realidad jurídica inevitable". Lex Social, vol 9, núm 2 (2019), pp. 2-6.

RODRIGUEZ COPÉ, M.L. "Conciliación y trabajo doméstico: un reto para las políticas sociolaborales del s. XXI. El decisivo papel de los Tribunales de Justicia”. Lex Social 2019 Vol. 9 núm $2 / 19$.

RUANO ALBERTOS, S. "Declaración de nulidad del despido de una empleada de hogar (Comentario de la Sentencia del Juzgado de lo Social no 31 de Madrid, de 16 de abril de 2008)". Aranzadi Social,. 2008. 
SALA FRANCO, T. "La relación laboral especial del Servicio del Hogar Familiar y el contrato de trabajo doméstico". Relaciones Laborales, núm. 4, 1986.

SANZ SAEZ, C.: La protección social de las empleadas de hogar. La desaparición del Régimen Especial de la seguridad Social y su integración en el Régimen General como Sistema Espacial: análisis actual y de futuro. Albacete. Bomarzo, 2017.

SELMA PENALVA, A., Novedades en el Régimen de Seguridad Social de los Empleados del Hogar y su comparación con las propuestas de reforma anteriormente anunciadas. Actualidad Laboral, núm. 2, Sección Estudios, T. 1, La Ley, I-2012.

SEMPERE NAVARRO, A.V; GARCÍA BLASCO, J.; GONZALEZ LABRADA, M.; CARDENAL CARRO, M. Derecho de la Seguridad y Salud en el trabajo. Madrid: Civitas, 2001. 